\title{
THE DETERMINATION OF INULIN BY LITTLE'S METHOD
}

\author{
BY \\ F. W. DIGGINS AND P. H. SANDERSON \\ From the Medical Unit, St. Mary's Hospital, London
}

(RECEIVED FOR PUBLICATION OCTOBER 9, 1953)

When inulin is determined in plasma by methods employing diphenylamine it is found that inulin-free plasma gives rise to an appreciable colour in the blank. Most of this is due to glucose, and the blank can be considerably reduced by treating the plasma with yeast (Alving, Rubin, and Miller, 1939; Harrison, 1942), or by curtailing the time of heating with the diphenylamine reagent, which reduces the colour due to glucose more than that due to inulin (Barnett, Blacket, Depoorter, Sanderson, and Wilson, 1950). Recently Little (1949) has proposed a method in which glucose is destroyed by heating the plasma filtrate in a boiling water-bath at a strongly alkaline reaction.

In the course of some inulin clearance determinations in this laboratory, using Little's method for inulin, unexpectedly low clearances were found in healthy medical students. The source of the error was found to be the heating with alkali, which was causing destruction not only of glucose but also of some of the inulin.

\section{Methods}

The inulin used in the clearance experiments was Kerfoot's sterile, pyrogen-free solution, prepared in ampoules for intravenous use. The ampoules were immersed in boiling water just long enough to allow complete re-solution of the precipitated inulin. In preparing standards, a specimen of dry inulin obtained from Messrs. Hopkins and Williams (not A. R.) was used; it was dissolved in water with as little heating as possible. Inulin was determined in plasma filtrates, urine dilutions, and aqueous solutions by Little's method and by Harrison's method. In the first, $4 \mathrm{ml}$. of solution and $1 \mathrm{ml} .4 \mathrm{~N} . \mathrm{NaOH}$. are heated in a boiling water-bath for 10 minutes, the mixture is cooled, $10 \mathrm{ml}$. of diphenylamine reagent is added and the mixture heated in the water-bath for a further 45 minutes. In the second method $5 \mathrm{ml}$. of solution, previously treated with yeast and with deproteinizing agents in the case of plasma, is heated for 45 minutes with $10 \mathrm{ml}$. diphenylamine reagent in a boiling water-bath. The extinction at $625 \mathrm{~m} \mu$ was measured in a Unicam spectrophotometer, model
S.P. 500. Proteins were removed from plasma by the cadmium hydroxide method (Fujita and Iwatake, 1931) using a dilution of 1 in 20 . The diphenylamine reagent used was that described by Harrison (1942).

\section{Results}

Table I shows the results obtained by the two methods on one specimen of plasma and one specimen of urine obtained during a clearance determination on a normal healthy subject.

TABLE I

RESULTS OBTAINED BY TWO METHODS

\begin{tabular}{|c|c|c|c|c|}
\hline & & & \multicolumn{2}{|c|}{ Inulin (mg. $100 \mathrm{ml}$ ) } \\
\hline & & & Harrison's Method & Little's Method \\
\hline $\begin{array}{l}\text { Plasma } \\
\text { Urine }\end{array}$ & & $\ldots$ & $\begin{array}{l}34 \cdot 3 \\
207\end{array}$ & $\begin{array}{c}25 \cdot 4 \\
124\end{array}$ \\
\hline
\end{tabular}

It will be noted that, while the figures obtained by Little's method are the lower in both cases, the reduction is far greater in the case of urine. The rate of urine flow at this time was $18.3 \mathrm{ml}$. per minute, giving an inulin clearance of $89 \mathrm{ml}$. per minute by Little's method and of 110 by Harrison's method. In three other clearance experiments on young healthy male subjects in whom inulin was estimated by Little's method only, figures of 69 (mean of nine periods), 96 (mean of 10 periods) and 74 (mean of 11 periods) were obtained. In all these experiments, as well as that recorded in Table I, urine dilutions as well as plasma filtrates were treated with alkali before heating with diphenylamine.

The effect of omitting the heating with alkali during the determination of standard inulin solutions was therefore tried. Solutions containing $2.5 \mathrm{mg} . / 100 \mathrm{ml}$. were prepared $(a)$ from the dry inulin sample by weighing, and $(b)$ from the solution in ampoules by diluting in accordance with the concentration (10\%) stated by the makers. To $4 \mathrm{ml}$. of each solution $1 \mathrm{ml}$. of $4 \mathrm{~N} . \mathrm{NaOH}$ was added and the tubes heated for 10 minutes, cooled, 
and treated with diphenylamine as before. A second series of tubes was treated with alkali in this same way, but the heating at this stage was omitted; the diphenylamine reagent was added at once and the colour was developed in the usual way. The results are shown in Table II.

TABLE II

EFFECT OF OMITTING HEATING WITH ALKALI

\begin{tabular}{c|c|c}
\hline & \multicolumn{2}{|c}{$\mathrm{E}_{625}^{1 \mathrm{~cm} .}$} \\
\cline { 2 - 3 } Inulin Solution & $\begin{array}{c}\text { Heated with Alkali } \\
\text { before Diphenylamine }\end{array}$ & $\begin{array}{c}\text { No Heating } \\
\text { with Alkali }\end{array}$ \\
\hline $\begin{array}{c}2.5 \mathrm{mg} . / 100 \mathrm{ml} \text {. from } \\
\text { dry specimen } \\
\begin{array}{c}2.5 \mathrm{mg} . / 100 \mathrm{ml} \text {. from } \\
\text { solution in ampoule }\end{array}\end{array}$ & $0.560,0.560$ & $0.830,0.830$ \\
\hline
\end{tabular}

The apparent destruction of inulin by alkali was thus $33 \%$ in the case of the dry specimen and $69 \%$ in the case of the ampoule solution. It was at fir $t$ thought that hydrolysis to fructose might have occurred during the heating required to dissolve the inulin. Table III, however, shows that both specimens of inulin contained only negligible quantities of fermentable carbohydrate, as judged by the diminution in colour produced by previous exposure to a yeast suspension. The ability of the yeast to destroy fructose is shown by the experiment with fructose as substrate.

TABLE III

RESULTS USING ,FRUCTOSE OR SUBSTRATE

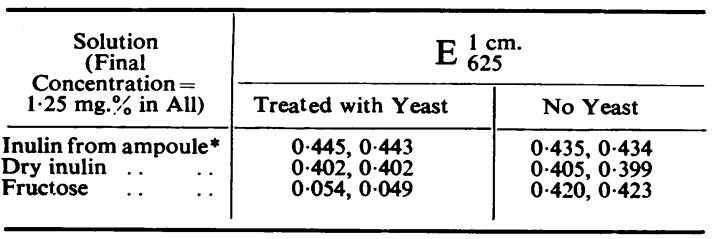

* Diluted on basis of maker's estimate of $10 \%$ in original solution.

It was found that the amount of inulin destroyed in a given preparation was not significantly increased by prolonging the period of heating with alkali beyond 10 minutes. Table IV shows the extinctions

TABLE IV

EXTINCTIONS AFTER HEATING DRY SAMPLES WITH ALKALI

\begin{tabular}{c|c}
\hline $\begin{array}{c}\text { Time of Heating } \\
\text { with Alkali } \\
\text { (Minutes) }\end{array}$ & $\mathrm{E}_{625}^{1 \mathrm{~cm} .}$ \\
\hline 10 & $0 \cdot 592,0.596$ \\
20 & $0 \cdot 598,0.599$ \\
30 & $0.595,0.580$ \\
\hline
\end{tabular}

obtained after heating a solution of the dry sample of inulin with alkali for 10, 20, and 30 minutes.

If a constant proportion of inulin were destroyed in standards, plasma filtrates, and urine dilutions it would be of no moment in the determination of inulin clearance, since what is required is the value of the ratio $\frac{U}{r}$, rather than the absolute value of either numerator or denominator. It was found, however, that the destruction of inulin in plasma filtrates was always less than in urine dilutions and standards (see Table I). The reason for this was not investigated, but it may be significant that when the $4 \mathrm{~N} \cdot \mathrm{NaOH}$ is added to $\mathrm{Cd}(\mathrm{OH})_{2}$ plasma filtrates a precipitate is formed. (The $\mathrm{NaOH}$ used in precipitating proteins was $1 \mathrm{~N}$, as recommended by Little, rather than $1.1 \mathrm{~N}$ as originally proposed by Fujita and Iwatake (1931); this minimizes the risk of obtaining an alkaline filtrate, which Shock (1944) has shown to cause serious losses of inulin.) This precipitate is probably $\mathrm{Cd}(\mathrm{OH})_{2}$ : if so, it must remove some of the hydroxyl ions from solution, and this would be expected to diminish the rate of destruction of carbohydrate by atmospheric oxygen.

\section{Discussion}

It is clear that the preparations of inulin studied, though substantially free from fermentable carbohydrate, were far from homogeneous, since they contained varying amounts of alkali-labile polymers. The data in Little's paper indicate that not more than about $4 \%$ of the inulin he used was alkalilabile, but this sample had been specially purified. Dr. J. M. Ledingham has informed us that he has encountered the same difficulty with a dry sample of Kerfoot's inulin in the course of tissue inulin determinations by the method of Ross and Mokotoff (1951), in which treatment with alkali is necessary; up to $50 \%$ of the inulin was lost at this stage. By boiling with alkali and recrystallizing he has been able to obtain a product of which not more than $2 \%$ is alkali-labile.

The inulin prepared by Messrs. Kerfoot in ampoules for intravenous use appears satisfactory for inulin clearance determinations, since normal values are obtained in normal subjects when the inulin determinations are carried out by the method of Barnett and his colleagues or by Harrison's method. When tissue inulin determinations are required, and heating with alkali cannot be avoided, purification of the inulin on the lines suggested by Dr. Ledingham will be necessary. The experience of the authors suggests that ordinary recrystallization, even if repeated several times, will not overcome the difficulty. 


\section{Summary}

When inulin which has not been specially purified is estimated by Little's method serious losses may occur during the heating with alkali. The proportion of inulin destroyed may be different in plasma filtrates and urine dilutions, in which case erroneous inulin clearances will be obtained.

\section{REFERENCES}

Alving, A. S., Rubin, J., and Miller, B. F. (1939). J. biol. Chem., 127,609 .

Barnett, A. J., Blacket, R. B., Depoorter, A. E., Sanderson, P. H. and Wilson, G. M. (1950). Clin. Sci., 9, is1.

Fujita, A., and Iwatake, D. (1931). Biochem. Z., 242, 43.

Harrison, H. E. (1942). Proc. Soc. exp. Biol., N.Y., 49, 111

Little, J. M. (1949). J. biol. Chem., $180,747$.

Ross, G., and Mokotoff, R. (1951). Ibid., 190, 659.

Shock, N. W. (1944). Jbid., 152, 169. 